\title{
EX VIVO EVALUATION OF THE ROOT CANAL MORPHOLOGY OF MESIAL ROOT OF PERMANENT MANDIBULAR FIRST AND SECOND MOLARS USING CBCT
}

\author{
Navneet Kaur Arora1, Shantun Malhotra², Kanwalpreet Kaur Bhullar', Harjeet Singh4, Kirandeep Kaur 5 \\ ${ }^{1}$ Student, Department of Conservative Dentistry and Endodontics, Sri Guru Ram Das Institute of Dental Sciences and Research, \\ Amritsar. \\ ${ }^{2}$ Reader, Department of Conservative Dentistry and Endodontics, Sri Guru Ram Das Institute of Dental Sciences and Research, \\ Amritsar. \\ ${ }^{3}$ Professor, Department of Conservative Dentistry and Endodontics, Sri Guru Ram Das Institute of Dental Sciences and Research, \\ Amritsar. \\ ${ }^{4}$ Assistant Professor, Department of Anaesthesiology, GMC, Amritsar. \\ 5Student, Department of Oral \& Maxillofacial Surgery, Sri Guru Ram Das Institute of Dental Sciences and Research, Amritsar.
}

\section{ABSTRACT}

\section{BACKGROUND}

As it has been well proven in the literature that one of the predominant reasons for the failure of root canal treatment is the lack of thorough knowledge of the pulp anatomy and its frequent variations. It is very important for operators to visualise the internal anatomic relationships of teeth before undertaking endodontic therapy. Cone beam computed tomography (CBCT) technology, with its accurate and high-quality three-dimensional representations of anatomic structures offers tremendous improvements in diagnostic capabilities.

The aim of this study was to evaluate the root canal configuration and minimum width of dentin at the danger zone area of mesial roots of first and second mandibular permanent molars using cone beam computed tomography in vitro.

\section{MATERIALS AND METHODS}

Fifty freshly extracted permanent mandibular first and fifty mandibular second molars were collected and scanned using cone beam computed tomography and analysed using Dicom software for this descriptive study. Descriptive statistics were used to find out the root canal configuration and minimum width of dentin at the danger zone area. One way, ANOVA and Post-hoc statistical tests were done.

\section{RESULTS}

The results revealed that Vertucci type IV configuration was most prevalent in mesial roots of mandibular first molars (56\%-64\%) as well as in mandibular second molars (52\%-64\%). Type II, III and VIII configurations were also found. The mean width of dentin at the distal (furcal) surface concavity for mesiobuccal canal of mandibular first and second molar was found to be 0.90-0.97 mm and 0.95-0.98 $\mathrm{mm}$ respectively and for mesiolingual canal, it was 1.03-1.08 $\mathrm{mm}$ and 0.93-0.94 mm respectively for mandibular first and second molars.

\section{CONCLUSION}

Vertucci Type IV configuration has been found to be the most prevalent in both mandibular first and second molars and the width of dentin at the danger zone area is between $0.90 \mathrm{~mm}$ and $1.03 \mathrm{~mm}$.

\section{KEYWORDS}

Mandibular Molars, Root Canal Anatomy, Mesial Root, Canal Configuration, Vertucci Classification, Cone Beam Computed Tomography (CBCT), Width of Dentin, Danger Zone Area.

HOW TO CITE THIS ARTICLE: Arora NK, Malhotra S, Bhullar KK, et al. Ex vivo evaluation of the root canal morphology of mesial root of permanent mandibular first and second molars using CBCT. J. Evolution Med. Dent. Sci. 2017;6(68):4883-4886, DOI: $10.14260 /$ Jemds/2017/1058

\section{BACKGROUND}

Endodontic treatment involves cleaning, shaping and obturation of the root canal system. For the success of root canal treatment, proper diagnosis, recognition of anatomy, effective chemomechanical debridement, eradication of intraradicular infection and proper canal shaping to facilitate obturation are very essential. ${ }^{1}$ Compromise in the quality of

Financial or Other, Competing Interest: None.

Submission 06-07-2017, Peer Review 13-08-2017,

Acceptance 19-08-2017, Published 24-08-2017.

Corresponding Author:

Dr. Navneet Kaur Arora,

D-17/1212, Street No.2,

Kartar Nagar, Chheharta, Amritsar.

E-mail: mail.navneetarora@gmail.com

DOI: $10.14260 /$ jemds $/ 2017 / 1058$

\section{(c) $($ ) $\odot$}

any of the steps can lead to failure of the same. A thorough understanding of the complexity of the root canal system is essential in endodontics for understanding the principles and problems of shaping and cleaning, for determining the apical limits and dimensions of canal preparations and for successful surgical procedures.

Endodontic procedure in multi-rooted teeth often possess a challenge to the Endodontist because of wide variation in morphology of root canals. As mandibular first molar erupts comparatively earlier than other teeth, hence there are more chances of caries and requirement of root canal treatment. The anatomical pattern of tooth root canals represents a wide variety of root canal configurations and anatomical complexities like accessory canals, lateral canals, apical deltas, fins which are inaccessible to routine treatment. ${ }^{2}$ The mesial roots of mandibular molars, approximately two $\mathrm{mm}$ 
below the furcation, are particularly subject to strip perforation as they have a greater concavity and subsequently limited thickness of dentine, which has been described as 'danger zone' (Abou-Rass et al 1980). ${ }^{3}$

Thus, correct visualisation of the complexities prior to starting the treatment, would be helpful in successful treatment outcome.

Numerous methods are being employed to analyse canal morphology, which include clearing method using methyl salicylate, direct observation under microscope, conventional and digital radiography and radiographic assessment enhanced with contrast medium but each has its own shortcomings. In the recent years, Cone beam computed tomography (CBCT) with its lower radiation and higher resolution than traditional CT scans, has produced valid root and canal details in three dimensions for diagnosis and prognosis in the context of endodontic therapy. ${ }^{4}$

Hence, the present study was conducted to evaluate the root canal configuration and minimum width of dentin at the danger zone area of mesial roots of first and second mandibular permanent molars using cone beam computed tomography in vitro.

\section{MATERIALS AND METHODS}

\section{Specimen Selection}

This descriptive study was conducted on freshly extracted fifty mandibular first and fifty mandibular second molars collected from the Department of Oral and Maxillofacial Surgery, Sri Guru Ram Das Institute of Dental Sciences and Research, Sri Amritsar. Consent was taken from the donors for the use of their extracted teeth in the study. The teeth with intact roots and without any carious lesions and cracks were selected. All samples were thoroughly cleaned and any soft tissue or calculus attached to the teeth was removed with ultrasonic scalers. The teeth were stored in 10 percent formalin.

\section{Sample Preparation}

The selected teeth were mounted in a straight line on modelling wax after determining the various aspects of the tooth i.e. buccal, lingual, mesial and distal, so as to maintain uniformity in the samples. The teeth were embedded to the level of cementoenamel junction in modelling wax blocks and one block comprising of five teeth only. Twenty blocks were made and scanned using cone beam computed tomography.

\section{Cone Beam Computed Tomography Scan}

Cone beam computed tomographic images for all teeth were obtained with CS9300 equipment (Carestream Healthcare India (P) Ltd) in the high resolution dental mode at $75 \mathrm{kV}, 4$ $\mathrm{mA}$ for a total scan time of 20 seconds. A single scout image, i.e. lateral view was taken in accordance with the teeth position and $360^{\circ}$ scan was acquired afterwards.

Study images were reconstructed from the volumetric dataset, in planes perpendicular to the selected tooth axes. True and oblique axial, coronal and sagittal images with a thickness of $0.09 \mathrm{~mm}$ and an interval of $0.09 \mathrm{~mm}$ were obtained. Cross-sectional images with a thickness of $0.09 \mathrm{~mm}$ and an interval of $1 \mathrm{~mm}$ were also prepared.
Image Assessment was performed and following Parameters were Evaluated by using Dicom Software

1. Root canal configuration based on Vertucci's classification.

2. Minimum width of dentin towards the furcation side, at the danger zone area.

The data recorded was analysed using One way, ANOVA and Post-hoc statistical tests.

\section{RESULTS}

In this study, it was found that in mesial root of mandibular left first molars, Vertucci type IV configuration was most prevalent (56\%) followed by type II (36\%) and type VIII (8\%). Similarly, in mesial root of mandibular right first molars, Vertucci type IV configuration was most prevalent (64\%) followed by type II (28\%), type III (8\%) configuration (Table 1). Also, in mandibular left second molars, Vertucci type IV configuration was most prevalent (64\%) followed by type II (12\%), type III (12\%), type VIII (8\%) and type I (4\%). Similarly, in mandibular right second molars, Vertucci type IV configuration was most prevalent $(52 \%)$ followed by type II (20\%), type I (16\%), type III (12\%) (Table 2). The mean width of dentin at the distal (furcal) surface concavity for mesiobuccal canal of mandibular first and second molar was found to be $0.90-0.97 \mathrm{~mm}$ and $0.95-0.98 \mathrm{~mm}$ respectively. For mesiolingual canal, it was $1.03-1.08 \mathrm{~mm}$ and $0.93-0.94 \mathrm{~mm}$ respectively for mandibular first and second molars (Table 3).

\begin{tabular}{|c|c|c|c|c|c|c|}
\hline & $\begin{array}{c}\text { Type } \\
\text { I }\end{array}$ & $\begin{array}{c}\text { Type } \\
\text { II }\end{array}$ & $\begin{array}{c}\text { Type } \\
\text { III }\end{array}$ & $\begin{array}{c}\text { Type } \\
\text { IV }\end{array}$ & $\begin{array}{c}\text { Type } \\
\text { VIII }\end{array}$ & Total \\
\hline Left First Molar & 0 & 9 & 0 & 14 & 2 & 25 \\
\hline Right First Molar & 0 & 7 & 2 & 16 & 0 & 25 \\
\hline Left Second Molar & 1 & 3 & 3 & 16 & 2 & 25 \\
\hline $\begin{array}{c}\text { Right Second } \\
\text { Molar }\end{array}$ & 4 & 5 & 3 & 13 & 0 & 25 \\
\hline Total & $\mathbf{5}$ & $\mathbf{2 4}$ & $\mathbf{8}$ & $\mathbf{5 9}$ & $\mathbf{4}$ & $\mathbf{1 0 0}$ \\
\hline $\begin{array}{r}\text { Table 1. Prevalence of Root Canal Configuration } \\
\text { based on Vertucci Classification }\end{array}$ \\
6
\end{tabular}

\begin{tabular}{|c|c|c|c|c|c|}
\hline Teeth & $\begin{array}{c}\text { Type } \\
\text { I \% }\end{array}$ & $\begin{array}{c}\text { Type } \\
\text { II \% }\end{array}$ & $\begin{array}{c}\text { Type } \\
\text { III \% }\end{array}$ & $\begin{array}{c}\text { Type } \\
\text { IV \% }\end{array}$ & $\begin{array}{c}\text { Type } \\
\text { VIII \% }\end{array}$ \\
\hline Left First Molar & 0 & 36 & 0 & 56 & 8 \\
\hline $\begin{array}{c}\text { Right First } \\
\text { Molar }\end{array}$ & 0 & 28 & 8 & 64 & 0 \\
\hline $\begin{array}{c}\text { Left Second } \\
\text { Molar }\end{array}$ & 4 & 12 & 12 & 64 & 8 \\
\hline $\begin{array}{c}\text { Right Second } \\
\text { Molar }\end{array}$ & 16 & 20 & 12 & 52 & 0 \\
\hline \multicolumn{7}{|c|}{ Table 2. Percentage Prevalence of Root Canal } \\
Configuration based on Vertucci Classification \\
\hline
\end{tabular}

\begin{tabular}{|c|c|c|c|c|c|c|}
\hline \multirow{2}{*}{ Teeth } & \multicolumn{3}{|c|}{$\begin{array}{c}\text { Mesiobuccal } \\
\text { Root Canal }\end{array}$} & \multicolumn{3}{c|}{$\begin{array}{c}\text { Mesiolingual } \\
\text { Root Canal }\end{array}$} \\
\cline { 2 - 7 } & N & Mean & \pm SD & N & Mean & \pm SD \\
\hline Left First Molar & 25 & 0.976 & 0.181 & 25 & 1.088 & 0.183 \\
\hline $\begin{array}{c}\text { Right First } \\
\text { Molar }\end{array}$ & 0.00025 & 0.908 & 0.168 & 24 & 1.033 & 0.208 \\
\hline $\begin{array}{c}\text { Left Second } \\
\text { Molar }\end{array}$ & 25 & 0.952 & 0.192 & 22 & 0.932 & 0.152 \\
\hline $\begin{array}{c}\text { Right Second } \\
\text { Molar }\end{array}$ & 25 & 0.980 & 0.216 & 21 & 0.943 & 0.194 \\
\hline p value & p = 0.521; Not Significant & \multicolumn{4}{c|}{$\begin{array}{c}\text { p = 0.014; } \\
\text { Significant }\end{array}$} \\
\hline Table 3. Width of Dentin at the Danger Zone Area \\
\hline
\end{tabular}




\begin{tabular}{|c|c|c|}
\hline Comparison & Mesiobuccal Root Canal (p value) & Mesiolingual Root Canal (p value) \\
\hline Left First Molar vs. Right First Molar & 0.660 & 0.787 \\
\hline Left First Molar vs. Left Second Molar & 0.978 & $0.047^{*}$ \\
\hline Left First Molar vs. Right Second Molar & 1.000 & 0.081 \\
\hline Right First Molar vs. Left Second Molar & 0.880 & 0.337 \\
\hline Right First Molar vs. Right Second Molar & 0.618 & 0.452 \\
\hline Left Second Molar vs. Right Second Molar & 0.965 & 0.998 \\
\hline \multicolumn{2}{|c|}{ Table 4. Multiple Comparison using Post-hoc Scheffe } \\
\hline
\end{tabular}

\begin{tabular}{|c|c|c|c|c|c|c|c|c|c|}
\hline & & \multirow{2}{*}{$\mathbf{N}$} & \multirow{2}{*}{ Mean } & \multirow{2}{*}{$\begin{array}{c}\text { Std. } \\
\text { Deviation }\end{array}$} & \multirow{2}{*}{ Std. Error } & \multicolumn{2}{|c|}{$\begin{array}{l}\mathbf{9 5 \%} \text { Confidence } \\
\text { Interval for Mean }\end{array}$} & \multirow{2}{*}{ Min } & \multirow{2}{*}{$\operatorname{Max}$} \\
\hline & & & & & & $\begin{array}{l}\text { Lower } \\
\text { Bound }\end{array}$ & $\begin{array}{l}\text { Upper } \\
\text { Bound }\end{array}$ & & \\
\hline \multirow{5}{*}{$\begin{array}{l}\text { Mesiobuccal } \\
\text { root canal }\end{array}$} & Left First Molar & 25 & 0.976000 & 0.1809236 & 0.0361847 & 0.901318 & 1.050682 & 0.7000 & 1.3000 \\
\hline & Right First Molar & 25 & 0.908000 & 0.1681269 & 0.0336254 & 0.838601 & 0.977399 & 0.6000 & 1.2000 \\
\hline & \begin{tabular}{|l|} 
Left Second Molar \\
\end{tabular} & 25 & 0.952000 & 0.1917464 & 0.0383493 & 0.872851 & 1.031149 & 0.5000 & 1.2000 \\
\hline & \begin{tabular}{|c|} 
Right Second \\
Molar \\
\end{tabular} & 25 & 0.980000 & 0.2160247 & 0.0432049 & 0.890829 & 1.069171 & 0.7000 & 1.4000 \\
\hline & Total & 100 & 0.954000 & 0.1893210 & 0.0189321 & 0.916435 & 0.991565 & 0.5000 & 1.4000 \\
\hline \multirow{5}{*}{$\begin{array}{l}\text { Mesiolingual } \\
\text { root canal }\end{array}$} & Left First Molar & 25 & 1.088000 & 0.1833030 & 0.0366606 & 1.012336 & 1.163664 & 0.7000 & 1.3000 \\
\hline & \begin{tabular}{|l|} 
Right First Molar \\
\end{tabular} & 24 & 1.033333 & 0.2078182 & 0.0424207 & 0.945579 & 1.121087 & 0.6000 & 1.3000 \\
\hline & Left Second Molar & 22 & 0.931818 & 0.1523979 & 0.0324913 & 0.864249 & 0.999388 & 0.7000 & 1.3000 \\
\hline & $\begin{array}{l}\text { Right Second } \\
\text { Molar }\end{array}$ & 21 & 0.942857 & 0.1938335 & 0.0422979 & 0.854625 & 1.031089 & 0.7000 & 1.3000 \\
\hline & Total & 92 & 1.003261 & 0.1941174 & 0.0202381 & 0.963060 & 1.043461 & 0.6000 & 1.3000 \\
\hline
\end{tabular}

\section{DISCUSSION}

Various methods used to study root canal morphology are replication technique, clearing technique, use of radiopaque dyes and radiographs, sectioning of teeth, and recently, spiral computed tomography (SCT) and cone beam computed tomography (CBCT). There are numerous advantages of Cone Beam Computed Tomography. It can be conveniently performed when required and acquires volumetric data in a single rotation with a short scan time. Also, it produces quality images with higher spatial resolution and poses fewer hazards to patients because of the reduced radiation dose required. Cone Beam Computed Tomography utility and relevance to the practise of endodontics is reported with increasing frequency. ${ }^{5}$ Hence, CBCT was used in this study to visualise the mesial root canal configuration according to Vertucci's classification and to measure the minimum thickness of dentin at the danger zone area in permanent mandibular first and second molars.

In this study, it was found that in mesial root of mandibular first molars, type IV configuration was most prevalent (56\%-64\%) followed by type II (28\%-36\%), type III (8\%), and type VIII (8\%) configuration. This is consistent with the findings of most of the earlier studies, except the studies by Zaatar et al. ${ }^{6}$ and Al-Nazhan ${ }^{7}$ which reported type II being the most prevalent followed by type IV. Identification, preparation, and obturation of type IV, type II, and type VIII are relatively straightforward. However, identification of canals in type III, where the canal divides within the root, is more difficult. The biomechanical preparation needs extra efforts, because failure to debride and disinfect this complex anatomy might have a direct effect on the treatment outcome. There are published reports indicating the presence of type VIII configuration in the mesial root, with the incidence of $0.2 \%$ to $5 \%{ }^{8}$
In this study, it was found that in mandibular second molars, type IV configuration was most prevalent (52\%-64\%) followed by type II (12\%-20\%). The results were consistent with the results obtained by a study done by NeelaKantan et al on the morphology of the canal and the root of the second mandibular molar in Indian population. ${ }^{9}$ The most prevalent type of root canal system was type IV of Vertucci (52.3\%) and then type II (35\%). Also, Sadeghi et al ${ }^{10}$ studied on the first and second mandibular molar teeth in an Iranian population and reported that the prevalence of different type of canals in mesial root of second mandibular molars were as follows: $6 \%$ type I, $26 \%$ type II, $62 \%$ type IV, $4 \%$ type V, $2 \%$ type VI. Similarly, in a research done by Al-Qudah and Awawdeh ${ }^{11}$ in 2009 , the most prevalent type of root canals in the mesial root of second molar (40\%) was type IV of Vertucci system. Whereas, in a study of Rahimi et al. ${ }^{12}$ carried out in 2008 on the first and second mandibular molars in an Iranian population, $90 \%$ of the mesial roots of the mandibular second molars with double roots had two canals (Predominantly with a type II or III configuration).

The mean width of dentin at the distal (furcal) surface concavity for mesiobuccal canal of mandibular first and second molar was found to be $0.90-0.97 \mathrm{~mm}$ and $0.95-0.98$ $\mathrm{mm}$ respectively. For mesiolingual canal, it was $1.03-1.08 \mathrm{~mm}$ and $0.93-0.94 \mathrm{~mm}$ respectively for mandibular first and second molars. The mean width of dentin at the root concavity was $0.86 \pm 0.12$ according to Sauáia et al ${ }^{13}$ similar to that reported by Bower (1979), who found a mean value of $0.7 \pm 0.19 \mathrm{~mm}$, ranging from 0.3 to $1.3 \mathrm{~mm}$. In order to prevent strip perforations, coronal flaring should be limited and directed at the outer and thicker aspects of the canal walls. However, the minimum coronal enlargement necessary to allow apical filling and effective irrigation has not yet been established (Wu et al, 2005).14 Lim \& Stock (1987) ${ }^{15}$ have determined an arbitrary value of $0.3 \mathrm{~mm}$ as the minimum 
canal wall thickness that should remain after instrumentation to prevent perforation or vertical root fracture.

\section{CONCLUSION}

In this study, it was found that type IV configuration was most prevalent in mesial root of mandibular first molar (56\%-64\%) and in mandibular second molars (52\%-64\%) both. Type II, III and VIII configurations were also found and variations in the number of roots or canals and teeth with unusual root canal configurations have a definite impact on treatment. To achieve long-term success, clinicians must use all the armamentaria at their disposal to locate and treat the entire root canal system. The width of dentin approximately 2 $\mathrm{mm}$ apical to the furcation was found to be between $0.90 \mathrm{~mm}$ and $1.03 \mathrm{~mm}$. Hence, careful preparation should be undertaken to prevent strip perforation in this area.

\section{REFERENCES}

[1] Ingle JI, Slavkin HC. Modern endodontic therapy: past, present and future. Chap 1. In: Ingle JI, Bakland LK, Baumgartner JC. eds. Ingle's endodontics. $6^{\text {th }}$ edn. BC Decker, Hamilton: 2008:1-35.

[2] Chourasia HR, Meshram GK, Warhadpande M, et al. Root canal morphology of mandibular first permanent molars in an Indian population. Int J Dent Article ID 745152, 2012:6:1-6.

[3] Abou-Rass M, Frank AL, Glick DH. The anticurvature filing method to prepare the curved root canal. J Am Dent Assoc 1980;101(5):792-4.

[4] Cotton TP, Geisler TM, Holden DT, et al. Endodontic applications of cone beam computed tomography. J Endod 2007;33(9):1121-32.

[5] Matherne RP, Angelopoulos C, Kulild JC, et al. Use of cone-beam computed tomography to identify root canal systems in vitro. J Endod 2008;34(1):87-9.
[6] Zaatar EI, al-Kandari AM, Alhomaidah S, et al. Frequency of endodontic treatment in Kuwait: radiographic evaluation of 846 endodontically treated teeth. J Endod 1997;23(7):453-6.

[7] Al-Nazhan S. Incidence of four canals in root-canaltreated mandibular first molars in a Saudi Arabian sub-population. Int Endod J 1999;32(1):49-52.

[8] Zhang R, Wang H, Tian YY, et al. Use of cone-beam computed tomography to evaluate root and canal morphology of mandibular molars in Chinese individuals. Int Endod J 2011;44(11):990-9.

[9] Neelakantan P, Subbarao C, Subbarao CV, et al. Root and canal morphology of mandibular second molars in an Indian population. J Endod 2010;36(8):1319-22.

[10] Sadeghi M, Lahijani MS. An in vitro study of root canal anatomy in mandibular molars. J Dent Sch GYEAR 2004;22(1):96-103.

[11] Al-Qudah AA, Awawdeh LA. Root and canal morphology of mandibular first and second molar teeth in a Jordanian population. Int Endod J 2009;42(9):775-84.

[12] Rahimi S, Shahi S, Lotfi M, et al. Root canal configuration and the prevalence of $\mathrm{C}$-shaped canals in mandibular second molars in an Iranian population. J Oral Sci 2008;50(1):9-13.

[13] Sauáia TS, Gomes BP, Pinheiro ET, et al. Thickness of dentine in mesial roots of mandibular molars with different lengths. Int Endod J 2010;43(7):555-9.

[14] Wu MK, van der Sluis LW, Wesselink PR. The risk of furcal perforation in mandibular molars using GatesGlidden drills with anticurvature pressure. Oral Surg Oral Med Oral Pathol Oral Radiol Endod 2005;99(3): 378-82.

[15] Lim SS, Stock CJ. The risk of perforation in the curved canal: anticurvature filing compared with the stepback technique. Int Endod J 1987;20(1):33-9. 